\title{
Construction of a Tobamovirus Vector That Can Systemically Spread and Express Foreign Gene Products in Solanaceous Plants.
}

\author{
Koichi HORI and Yuichiro WATANABE* \\ Department of Life Sciences, Graduate School of Arts and Sciences, University of Tokyo, \\ Komaba, Meguro, Tokyo 153-8902, Japan \\ *Corresponding author E-mail address: solan@bio.c.u-tokyo.ac.jp
}

Received 11 November 2002; accepted 3 February 2003

\begin{abstract}
In present-day biology, a facile gene delivery system is required to study gene function in a high throughput way. The use of plant virus vectors that can introduce foreign or extra endogenous genes into plants attracts much attention. It is advantageous in that researchers need only minimal experience and results can be obtained in a short period of time. Here we describe infectious cDNA clones of the tomato mosaic tobamoviruses (ToMV) that were modified for facile insertion of foreign genes and which retained the ability to multiply in plants. This vector, named TocJ, was able to harbor the GFP gene from Aequorea victoria and systemically spread in some Solanaceous plants. TocJ would be suitable for the overexpression of foreign genes and the analysis of gene functions in various Solanaceous plants.
\end{abstract}

Key words: green fluorescent protein, systemic infection, tobamovirus vector.

\section{Abbreviations}

BCIP/NBT, 5-bromo-4-chloro-indolyl-phosphatase /nitrobluetetrazorium; BSA, bovine serum albumin; CP, coat protein; CS, context sequence; DIG, digoxigenin; dpi, days post inoculation; GFP, green fluorescent protein; hpi hours post inoculation; PVDF, polyvinylidene difluoride; sg mRNA, subgenomic messenger RNA; TMGMV tobacco mild green mosaic virus; TMV tobacco mosaic virus; ToMV, tomato mosaic virus; UTR, untranslated region.

\section{Introduction}

It has been shown that several viral vectors can be used for the transient expression of foreign genes in plants., such as peptides, proteins like antigens (Porta et al., 1994; Fitchen et al., 1995; Sugiyama et al., 1995; Turpen et al., 1995; Bendahmane et al., 1999) and antibody fragments (Franconi et al., 1999; Hendy et al., 1999; Roggero et al., 2001). This strategy has an impact on basic research and as well as plant biotechnology, since the expression level of foreign proteins is relatively high and rapid accumulation might help to bypass its possible toxicity to plants.

Tobamoviruses multiply rapidly in infected plants and many attempts have therefore been made to modify and utilize their genomes to express foreign genes (Takamatsu et al., 1987; Dawson et al., 1989; Takamatsu et al., 1990b; Donson et al., 1991; Kumagai et al., 1993; Lim et al., 2002). Of the TMV-encoded gene products, coat protein (CP) is the most abundantly expressed. Initially, a tobamovirus vector was constructed by replacing the $\mathrm{CP}$ coding region with a foreign gene sequence. These vectors could multiply in infectious leaves and express foreign proteins (Takamatsu et al., 1987). However, they could not spread out to other leaves, because intact $\mathrm{CP}$ is necessary for the systemic spread of the virus. To overcome this problem, several approaches were used to express foreign genes with $\mathrm{CP}$ expression retained to some extent.

Earlier we reported a ToMV based vector, where a readthrough $3^{\prime}$ context sequence $\left(3^{\prime} \mathrm{CS}\right.$ ) was inserted between the coat protein gene and the foreign gene sequences as an in-frame junction (Hamamoto et al., 1993; Sugiyama et al., 1995). The 3 ' $\mathrm{CS}$ was characterized as a six - base sequence that follows the stop codon for the $126 \mathrm{~K}$ RNA dependent RNA polymerase (RdRP) gene and permits readthrough of the stop codon (Skuzeski et al., 1991), giving rise to the synthesis of their $\mathrm{N}$ ' coterminal 183K RdRP. The vector could multiply in inoculated leaves and also spread systemically. 
The 3' CS sequence allowed both intact $\mathrm{CP}$ and a $\mathrm{CP}$-foreign protein fusion to be produced at a ratio of $20: 1$.

Dawson et al. made a tobamovirus vector that has an extra CP subgenomic mRNA (sgRNA) promoter to drive foreign gene expression (Dawson et al., 1989). They replaced the CP ORF with a foreign gene ORF and then added a second-TMV CP sgRNA promoter and CP ORF. The first CP sgRNA promoter in this TMV-based hybrid vector is an extra one and drives foreign gene expression by

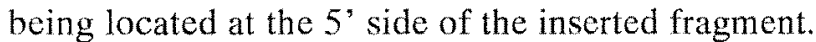
Initially, this approach faced the problem of genomic instability with a loss of foreign gene sequences as a result of deletion of DNA between duplicated sequences. To overcome this, the vector was improved by using a genome fragment of a heterologous tobamovirus including sgRNA promoter and $\mathrm{CP}$ ORF. The new vector, called $30 \mathrm{~B}$, showed good stability of the genome organization during multiplication in plants (Shivprasad et al., 1999).
Like these, a number of tobamovirus-based expression vectors have achieved success in the expression of foreign genes but in most cases such a tobamovirus vector could challenge only Nicotiana benthamiana. This time, we manipulated the ToMV genome to obtain two types of vectors and tried to express GFP as a representative of foreign genes on several Solanaceous plants.

\section{Materials and Methods}

\section{Plant materials}

Nicotiana benthamiana, Nicotiana tabacum, Lycopercicon esculentum, Capsicum annuum var. angulosum, Cucurbita pepo, Perilla frutescens var. crispa and Mentha piperita were used in this study. All plants were maintained at $23^{\circ} \mathrm{C}$ during a $16 \mathrm{~h}$ photoperiod and $8 \mathrm{~h}$ dark period.

\section{Plasmid Constructions}

Virus cDNAs used in this study were ToMV

\section{A}

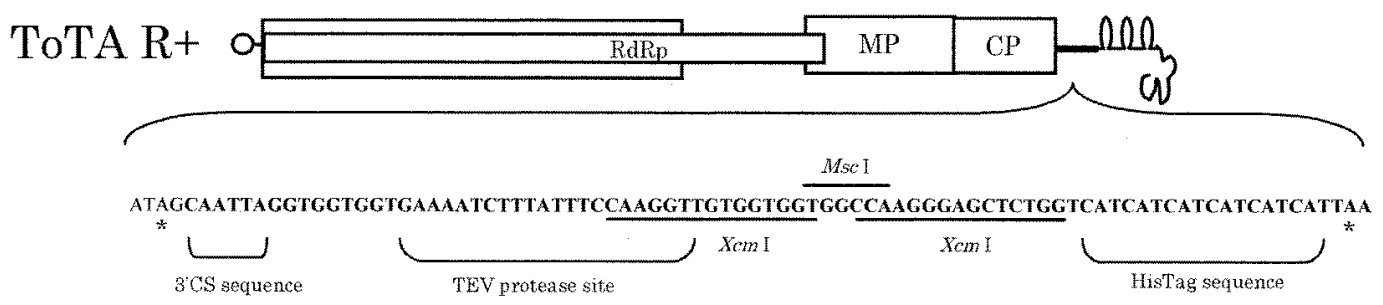

$\mathrm{B}$

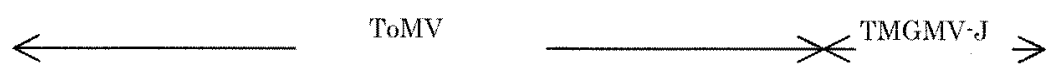

TocJ

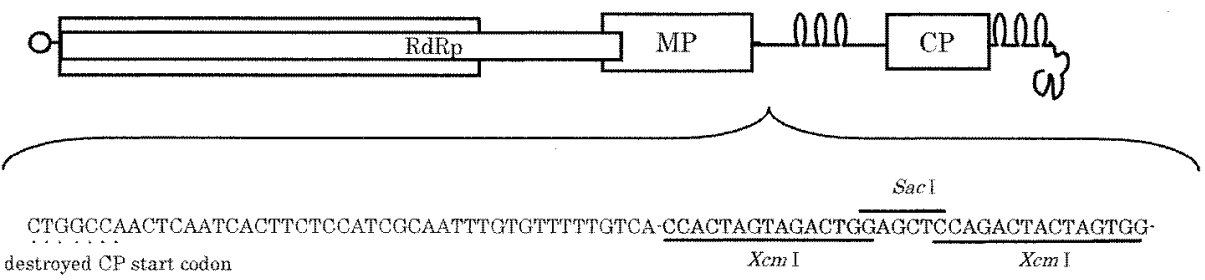

C

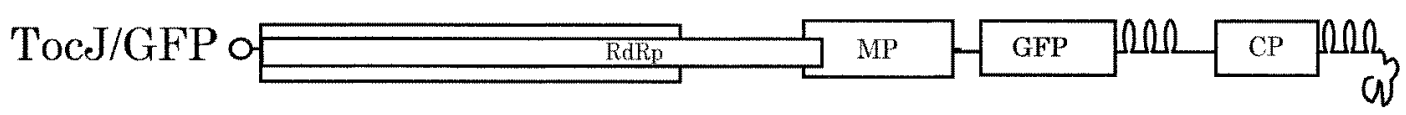

Fig. 1 Schematic represention of vectors. 5' - cap structures are depicted by circles. RNAdependent RNA polymerase, movement protein (MP) and coat protein (CP) genes are represented by rectangles. The underlined lines indicate inserted restriction sites.

(A) Construct of ToTA R+ vector. The asterisks denote stop codons.

(B) Construct of TocJ vector. Pseudoknot regions derived from ToMV and TMGMV are shown by bulges. The dots in multi-cloning sites (MCS) denote the mutated nucleotides surrounding the start codon of TMV CP. (C) Construct of TocJ/GFP. 
(GenBank accession no. X02144) (Ohno et al., 1984; Meshi et al., 1986) and TMGMV Japanese strain (TMGMV - J, GenBank accession AB078435) (Morishinma et al., 2003). The pTLW3 (Meshi et al., 1986) was the starting plasmid to which modifications were introduced for the construction of ToTA R+ and TocJ vectors. For convenience, the acronym ' $p$ ' of the name of the template DNA was deleted in naming each virus vector. Fig. 1 shows the structures of the ToTA R+ vector (A), the TocJ vector (B) and TocJ/GFP (C). By PCR assisted mutagenesis (Imai et al., 1991) with primers a and b (Table 1), one endogenous $X \mathrm{cmI}$ site of pTLW3 was diminished by C4394T substitution to make pTLW3 $\triangle X c m$ I. The PCR products were self-1igated by the TAKARA blunting kination ligation kit (TAKARA).

Construction of pToTA R+: The segment of [3'CS - tobacco etch virus (TEV) protease site one $X c m I$ site - spacer SacI site - another XcmI site -.. His tag site] was inserted into pTLW3 $\triangle X c m$ I by PCR with primers $\mathrm{c}, \mathrm{d}$ and e (Table 1). At first, one fragment was PCR-amplified with pTLW3 $\triangle X c m$ I and primers $\mathrm{c}$ and e. Next, the fragment, primers $d$ and $\mathrm{e}$, and pTLW3 $\triangle X \mathrm{CmI}$ were used for the next PCR amplification. The PCR product was digested with SacI and self-ligated to get pToTA R+. The final pToTA $\mathrm{R}+$ has an inserted sequence of ATAGCAATTAGGTGGTGGTGAAAATCTTTATTTCCAAGGTTGTGGTGGTGGCCAAGGGAGCTCTGGTCATCATCATCATCATCATTAATG

(underlined; $X \mathrm{CmI}$ site) between nucleotides 6178 and 6183 of ToMV.

Construction of pTocJ: PCR was performed with pTLW3 $\triangle X c m I$ and primers $f$ and $g$ (Table 1) to induce substitution of $\mathrm{TA}-\mathrm{to}-\mathrm{GC}$ at nucleotides 6327-8 into pTLW3 $\triangle X \mathrm{~cm}$ I to create NaeI site in this position. The product was treated with $\mathrm{NaeI}$ and self-ligated to get pTLW3 $\triangle X \mathrm{CmI}+\mathrm{NaeI}$. Next, the fragment of nt 5502-6356 of TMGMV-J was amplified with primers $\mathrm{h}$ and $\mathrm{i}$ which contain $\mathrm{Ngo}$ MIV (isoschizomer of NaeI) and MluI sites, respectively (Table 1). This fragment was treated with Ngo MIV and MluI and inserted into compatibly digested pTLW3 $\triangle X \mathrm{cmI}+\mathrm{NaeI}$. The start codon of ToMV CP ORF was diminished by PCR with primers $j$ and $k$ (Table 1). Lastly, the ToMV coat protein sequence (nt 5748-6182) was replaced with a multiple cloning site by PCR with primers 1 and $m$ (Table 1). The PCR products were digested with $S a c I$ and self-ligated to obtain pTocJ. The final TocJ has a cloning-sites sequence CCACTAGTAGACTGGAGCTCCAGACTACTAGTGG (underlined; $X \mathrm{cmI}$ site) [one $X \mathrm{cmI}$ site - spacer SacI site another $X \mathrm{~cm} I$ site] between nucleotide 5747 and 6183 of ToMV. The fragment of nucleotides 5502 6356 of TMGMV $\mathrm{J}$ was joined downstream of ToMV nucleotides 6325 and the following the GCCGGC- linker sequence.

The ORF of G3 green fluorescent protein (G3 GFP) was amplified PCR with primers $\mathrm{n}$ and $\mathrm{o}$ (Table 1) from LQwt:G fus (Kawakami and Watanabe, 1997). G3 GFP is a spectrometric variant which matches common FITC filter sets (Ogawa et

Table 1 Oligonucleotides used in this study

\begin{tabular}{|c|c|c|c|}
\hline & Oligonucleotide names & Sequences ${ }^{11}$ & Nucleotides \\
\hline a & $\mathrm{L}-\mathrm{KpnI}-\mathrm{cut}-\mathrm{Rv}$ & САCСАCTCTTTCTCTGaTACCATAAACACGTT & 32 \\
\hline$b$ & L-KpnI-cut-F & ATGTTACAACTTTTATCGGTAATACCGTCATCATTG & 36 \\
\hline c & $\mathrm{T} 1-\mathrm{RV}$ & ataaagattttcaccaccacctaattgctatGATGCAGGTGCAGAGGTCC & 50 \\
\hline d & $\mathrm{T} 2-\mathrm{RV}$ & gagctcecttggccaccaccacaaccttggaaataaagattttcaccacc & 50 \\
\hline e & $T 3-F$ & gagctctggtcatcatcatcatcatcattaatgATGCATAGGTGCTGAAA & 50 \\
\hline $\mathrm{f}$ & ToMV3'NaeI+F & ATGTCCGCCGGCACGTAAAAAAAGCG & 26 \\
\hline $\mathrm{g}$ & ToMV3'Nael+RV & TACGTGCCGGCGGACATATATGAACC & 26 \\
\hline h & TMGMV-5'-2Nael & TCGAGgccggcTGTGAAACTCGAAAGGTTCC & 31 \\
\hline I & TMGMV-3’MluI & CGTCGacgcgTGGGCCGCTACCCGCGGTTA & 30 \\
\hline $\mathrm{j}$ & ToMV-CP-ATG->CTG-R & CCTGCotggccaGATTTAATACGAATCAGAATCC & 34 \\
\hline $\mathrm{k}$ & $\mathrm{ToMV}-\mathrm{CP}-\mathrm{ATG}->\mathrm{CTG}-\mathrm{F}$ & CCACCctggecaACTCAATCACTTCTCCATCG & 32 \\
\hline 1 & ToMV-chi-clo-F & gactcgagctccagactactagtggATGCATAGGTGCTGAAATATAAAG & 49 \\
\hline $\mathrm{m}$ & ToMV-chi-clo- $\mathrm{R}$ & gtctcgagctccagtctactagtggTGACAAAAACACAAATTGCG & 45 \\
\hline n & $G F P-$ for $-T-F-3$ & TATGAGTAAAGGAGAAGAACT & 21 \\
\hline 0 & GFP-for - bam $-\mathrm{r}$ & TGGATCCTTATTTGTATAGTTCATCCATGC & 30 \\
\hline
\end{tabular}

"Underlined letters indicate restriction sites.

Lower case letters indicate nucleotides in the primers designed to introduce mutations or cloning sites. 
al., 1995). The fragment encoding GFP was inserted to ToTA R+ and Toc. TA cloning sites to make ToTA R+/GFP and TocJ/GFP (Fig. 1).

\section{In vitro transcription}

The vector template DNA was linearlized with MluI prior to in vitro transcription to make a runoff transcription. The in vitro transcription reaction was performed using $1 \mu \mathrm{g}$ linearized vector DNA, 50 unit T7 RNA polymerase (Invitrogen), $1 \mathrm{mM}$ ATP, $1 \mathrm{mM}$ UTP, $1 \mathrm{mM}$ CTP, $0.5 \mathrm{mM}$ GTP, and $0.52 \mathrm{mM}$ m7GpppG (NEB) as a cap analog in 40 $\mathrm{mM}$ Tris- $\mathrm{HCl}(\mathrm{pH} 8.0), 8 \mathrm{mM} \mathrm{MgCl}_{2}, 2 \mathrm{mM}$ spermidine $-(\mathrm{HCl})_{3}, 25 \mathrm{mM} \mathrm{NaCl}_{2}$, and $1 \mathrm{mg} \mathrm{ml}^{-1}$ bovine serum albumin (BSA) for $60 \mathrm{~min}$ at $37^{\circ} \mathrm{C}$.

\section{Inoculation of transcripts to protoplasts and plants}

Protoplasts were prepared from $N$. tabacum BY-2 suspension culture cells and inoculated with an in vitro transcript using electroporation as described previously (Watanabe et al., 1987). Transcripts derived from $0.5 \mu \mathrm{g}$ of the template were used for electroporation. Protoplasts were harvested after 15 h culture at $28^{\circ} \mathrm{C}$.

Firstly transcripts were inoculated to six-week old $N$. benthamiana with carborundum. After 5 days, the inoculated leaves were homogenized in PBS buffer $\left(137 \mathrm{mM} \mathrm{NaCl}, 8.10 \mathrm{mM} \mathrm{Na}_{2} \mathrm{HPO}_{4}{ }^{-}\right.$ $12 \mathrm{H}_{2} \mathrm{O}, 2.68 \mathrm{mM} \mathrm{KCl}$ and $1.47 \mathrm{mM} \mathrm{KH}_{2} \mathrm{PO}_{4}$ ). The homogenates were then centrifuged for $10 \mathrm{~min}$ at $10,000 \mathrm{~g}$. The sap was inoculated on six--weeksold $N$. benthamiana, $N$. tabacum, $L$. esculentum, $C$. annuum var. angulosum, $C$. pepo, Perilla frutescens var. crispa and $M$. piperita .

\section{Northern blot analysis}

Total RNA was purified as previously described (Shirzadegan et al., 1991). Total RNAs were treated with $50 \%$ formamide and $2.2 \mathrm{M}$ formaldehyde in MOPS buffer $(20 \mathrm{mM}$ 4-morpholinepropanesulfonic acid, $5 \mathrm{mM}$ sodium acetate, $1 \mathrm{mM}$ EDTA, pH 7.0) and separated in 1\% agarose gels containing $20 \mathrm{mM}$ MOPS buffer. Then the RNAs were transferred onto Hybond $\mathrm{N}+$ membranes by capillary blotting. After drying at room temperature, the membranes were irradiated with a UV lamp 70,000 micro- $\mathrm{J} \mathrm{cm}^{-2}$ by UV crosslinker (Stratagene). The fragment of nucleotide 5502-6356 of TMGMV-J was subcloned in a pGEM-Teasy (Promega) vector, to get a pTMGMVprobe. DIGlabeled TMGMV antisense probes were transcribed from the pTMGMV probe template DNA using a DIG-RNA labeling kit (Roche). The TMGMV probe was hybridized with membranes at high stringency at $68^{\circ} \mathrm{C}$ overnight. Membranes were washed twice with $2 \mathrm{x}$ SSC containing $0.1 \%$ SDS for $15 \mathrm{~min}$ at $68^{\circ} \mathrm{C}$, and twice with $0.5 \mathrm{x}$ SSC containing $0.1 \%$ SDS for $15 \mathrm{~min}$ at $68^{\circ} \mathrm{C}$. The DIG-RNA probe was detected using Anti-Digoxigenin- $A b$ Fab fragments (Roche) and a BCIP/NBT Membrane Phosphates Substrate (KPL).

\section{Western blot analysis}

The total proteins were extracted with PBS buffer using disposable pestles in microcentrifuge tubes. The homogenates were then centrifuged for $10 \mathrm{~min}$ at $10,000 \mathrm{~g}$. Protein concentrations were determined by Bradford's method. The proteins were separated on $12 \%$ polyacrylamide gels containing $1 \%$ SDS (Laemmli, 1970) and transferred onto a PVDF membrane (Immobilon; Millipore) using an electroblotting system (BioRad). GFP and TMGMV CP were detected using anti-GFP antiserum (Santa Cruz biotechnogy) and anti-ToMV CP serum (Saito et al, 1989), respectively. The membranes were incubated for $30 \mathrm{~min}$ in Tris buffer $[50 \mathrm{mM}$ Tris$\mathrm{HCl}$ (pH7.5)] containing $150 \mathrm{mM} \mathrm{NaCl}$ and $5 \%$ skim milk and treated with respective antibodies for $2 \mathrm{~h}$. Subsequently they were treated with alkaline phosphates-linked goat anti-rabbit antibody (Cell Signaling technology) and BCIP/NBT Membrane Phosphates Substrate (KPL).

\section{Results and Discussion}

Limitations of a vector harboring long foreign sequences between the TOMV CP ORF and 3' UTR

In previous work, we developed ToMV-based 3' CS vectors (Hamamoto et al., 1993). In this work we introduced multiple cloning sites of 90 mer between the ToMV CP coding sequence and the 3' untranslated region (UTR) to construct ToTA R+ (Fig. 1A) to insert the foreign sequence. The 3' UTR, located downstream of CP ORF, consists of three pseudoknots followed by a tRNA-like structure (van Belkum et al., 1985; Takamatsu et al, 1990a).

When ToTA $\mathrm{R}+$ was inoculated into BY- 2 protoplasts, it was able to replicate and produce viral proteins (data not shown). However, when we inserted GFP sequences into the ToTA R+ vector, the virus could not multiply and produce CP or GFP to a level detectable by western blot analysis in plants or in BY - 2 protoplasts (data not shown).

The ToMV CP-3'UTR junction was therefore suitable for efficient expression of short peptides but inadequate for large-size foreign gene sequences. As an alternative method, we adopted a strategy to add an extra sgRNA promoter to the ToMV genome (Shivprasad et al., 1999). 
Introduction of an extra subgenomic promoter and 3'UTR into the ToMV genome

A new ToMV-based hybrid replicon vector, TocJ, was created by inserting heterologous sequences from TMGMV-J (Morishima et al., 2003, GenBank accession no. AB078435). The structure of TocJ from 5' to 3' is as follows (Fig. 1B). The first 5924 bp of the replicon comes from ToMV, from its original 5' end thorough to the 3'UTR. The original AUG start codon of the coat protein ORF was mutated to CUG. The main part of the coat protein, except for the +45 nt leader sequences, was replaced with $X \mathrm{~cm} \mathrm{I}$ restriction endonuclease sites that can generate a TA cloning site, with a 1-nt 3' thymidine overhang feasible for cloning PCR fragments (Kovalic et al., 1991) to allow insertion of foreign sequences. Subsequently foreign sequences would be expressed from the sgRNA promoter (Shivprasad et al., 1999; Grdzelishvili et al., 2000). Following the ToMV 3' UTR, the next 855 bp comes from the 3' sequence of TMGMV, including the CP sgRNA promoter, the CP ORF and the 3' UTR.

To look at its biological activity, TocJ was inoculated into BY-2 protoplasts. RNA samples were collected at $15 \mathrm{~h}$ post-inoculation (hpi) for Northern blot analysis. Both TocJ genomic RNA and
A

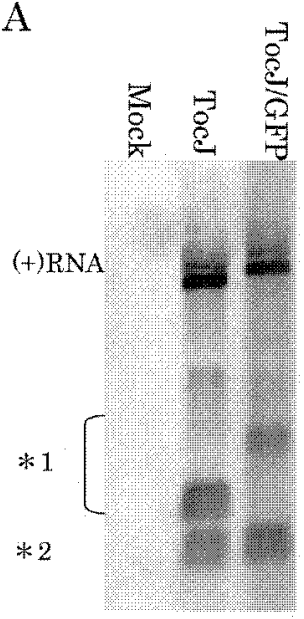

B

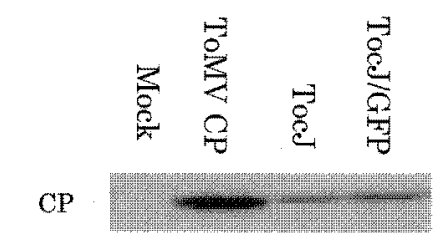

$\mathrm{C}$

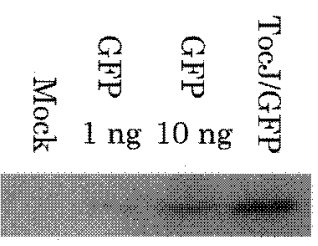

Fig. 2 Multiplication of tobamovirus vector TocJ in protoplasts. (A) Accumulation of RNAs of TocJ vectors in BY -2 protoplasts. Northern blot of total RNA extracted from protoplasts $10^{5}$ cell at 15 hpi was probed with TMGMV (5502 $\mathrm{nt}^{-}$ $6356 \mathrm{nt})$ positive-strand RNA-specific probe. *1 denotes sg mRNAs directed by ToMV CP sg mRNA promoter. ${ }^{*} 2$ denotes TMGMV CP sg mRNA.

Western blot analysis of (B) $\mathrm{CP}$ and (C) GFP produced in virus-inoculated $\mathrm{BY}-2$ protoplasts $0.25 \times 10^{5}$ cell at 15 hpi. Positive controls were $1 \mathrm{ng}$ and $10 \mathrm{ng}$ of GFP.
sgRNAs originating from the ToMV and TMGMV sgRNA promoters were detected as expected (Fig. $2 \mathrm{~A})$. It was thus confirmed that the introduced sgRNA promoter was functional.

When $N$. tabacum cv. Samsun was inoculated with TocJ, it showed mosaic symptoms after 6 days and SDS-PAGE analysis confirmed TMGMV CP accumulation (data not shown). These data indicated that the TocJ vector could replicate and spread systemically.

It is advantageous that the genomic RNA of virus vectors be encapsulated with $\mathrm{CP}$ to form virion particles because of their stability and high infectivity. To test this, protoplasts inoculated with TocJ were homogenized at 15 (hpi) and the sap inoculated onto the leaves of the local lesion host, Nicotiana tabacum cv. Xanthi-nc. Crude sap from protoplasts inoculated with TocJ produced as many local lesions as wild type ToMV, while a ToMV mutant with its coat protein replaced with GFP (LA C GFP) could not form virion particles nor elicit local lesions (Fig. 3). It was confirmed that TocJ progeny could form virus particles in infected tissues.

Expression of GFP by TocJ virus vector in Nicotiana benthamiana

The ORF of the GFP was amplified by PCR and inserted into the $X \mathrm{cmI}$ sites of TocJ to create TocJ/GFP (Fig. 1C). TocJ/GFP was inoculated into BY - 2 protoplasts and RNA was harvested at $15 \mathrm{hpi}$. Northern blot analysis confirmed that TocJ/GFP could replicate maintaining an intact GFP sequence (Fig. 2A). Expression of TMGMV CP and GFP
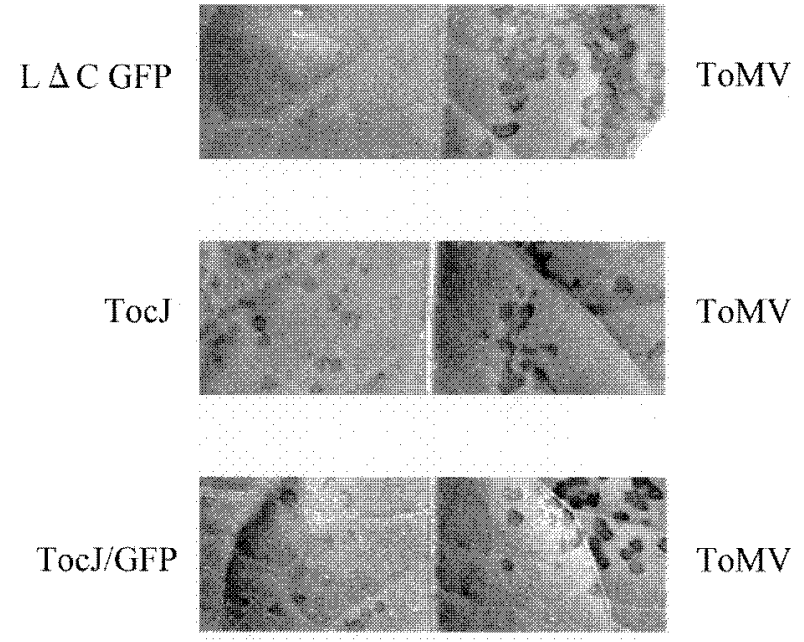

Fig. 3 Local lesions caused by saps extracted from BY-2 protoplasts. A ToMV mutant replaced coat protein to GFP (L $\triangle \mathrm{C}$ GFP), TocJ and TocJ/GFP were inoculated at the left sides of leaves; wild type ToMV was inoculated at the right halves. Photos were taken at $5 \mathrm{dpi}$. 
protein in TocJ/GFP - infected protoplasts was analyzed by Western blot. TMGMV CP was detected in both protoplasts infected with TocJ and those inoculated with TocJ/GFP (Fig. 2B). Accumulation of GFP protein in protoplasts inoculated with TocJ/GFP at $15 \mathrm{hpi}$ was estimated to be $125 \mathrm{ng}$ per $10^{5}$ cells (Fig. 2C). Extracts of infected protoplasts were inoculated onto leaves of local lesion hosts. TocJ/GFP induced local lesions (Fig. 3 ) as much as TocJ did. It was confirmed that TocJ/GFP formed intact virus particles.

The transcript of TocJ/GFP caused infection in inoculated $N$. benthamiana plants. TocJ/GFP infection produced fluorescent foci visible to the naked eye in the inoculated leaves of $N$. benthamiana by 3 days post-inoculation (dpi) (Fig. 4A). GFP fluorescence could be observed in upper, non-inoculated leaves at $7 \mathrm{dpi}$ (Fig. 4B) and by $12 \mathrm{dpi}$, GFP fluorescence had spread more widely (Fig. 4C). We analyzed accumulation levels of GFP and CP in these plants by western blot analysis. In TocJ/GFP-inoculated leaves, GFP accumulation increased till 7 $\mathrm{dpi}$, reached a plateau and leveled off at $12 \mathrm{dpi}$, however the level declined to some extent by 21 dpi. In upper leaves, where the virus moved in systemically, GFP started to accumulate a little at 3 dpi, but its accumulation increased to a high level by $12 \mathrm{dpi}$. The level seemed to be maintained by 21 dpi (Fig. 5A). In contrast to GFP accumulation, it seemed that $\mathrm{CP}$ accumulation increased for three weeks after inoculation in both inoculated and systemically infected leaves (Fig. 5B). Assuming that its accumulation reflects the degree of virus multiplication, virus multiplication did not always correlate with continuous accumulation of foreign genes. It would be necessary to examine the best

A

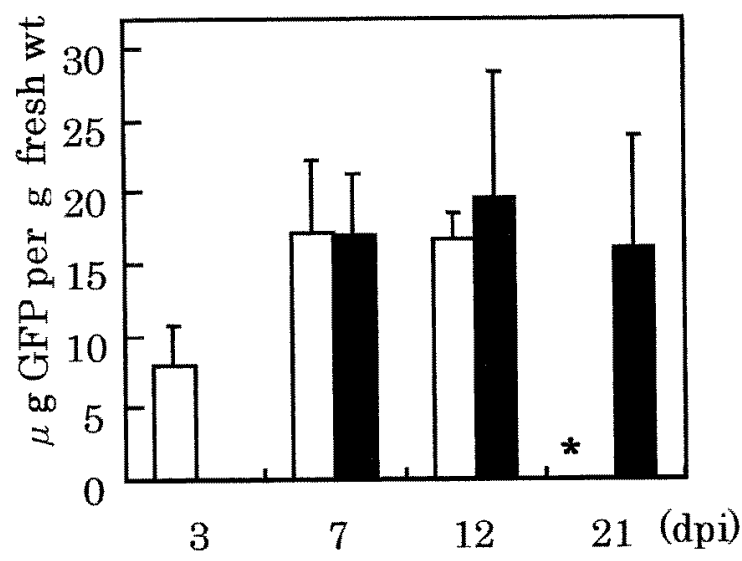

time to harvest foreign protein in inoculated tissues in each case.

TocJ/GFP could multiply on several kinds of Solanaceae family plants.

TocJ/GFP virus was also examined for its ability to express GFP in $N$. tabacum (Fig. 4D-F), Lycopercicon esculentum (Fig. 4G) and Capsicum annuum var. angulosum (Fig. 4H). As a result, GFP fluorescence was detected systemically in these plants. In contrast, when pumpkin (Cucurbita pepo), perilla (Perilla frutenscens var. crispa) and mint (Mentha piperita) plants were inoculated with TocJ/GFP, GFP fluorescence could not detected even at 7 dpi (data not shown). Thus, it appears that TocJ/GFP has a wide host range in the Solanaceae family. No visible symptoms were observed in $N$. tabacum and L. esculentum, however TocJ/GFP caused senescence, necrosis, leaf curling and dwarfness in nine-week old or older $N$. benthamiana plants, and complete withering in younger, sevenweek old plants (data not shown).

Based on these observations of GFP expression, it seems that the TocJ vector could be useful for foreign protein expression. However, due to its rather severe virulence, it may not be suitable for investigating the phenotypes caused by foreign genes in $N$. benthamiana.

The 30B.GFP produced systemic fluorescence later than 19 dpi on $N$. tabacum (Toth et al., 2002). On the other hand our TocJ/GFP produced systemic fluorescence as early as $7 \mathrm{dpi}$ in $N$. tabacum. It seems that the TocJ vector virus may spread more efficiently than the 30B.GFP vector in N. tabacum.

Recently Toth $e t a l$. reported a trial to improve the $30 \mathrm{~B}$ vector's ability to spread systemically. DNA

B

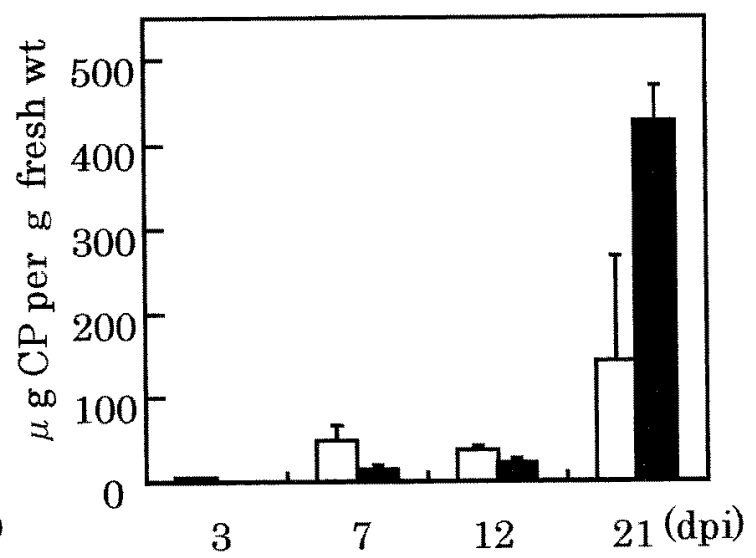

Fig. 5 Accumulations of GFP and CP in N. benthamiana inoculated with TocJ/GFP. Open and filled bars indicate accumulation in inoculated leaves, and that in systemically infected leaves, respectively. (A) Accumulation of GFP. The asterisk indicates that GFP level was below the detection limit. (B) Accumulation of CP. The upper 3-4 leaves above the inoculated ones were not present at $3 \mathrm{dpi}$. 

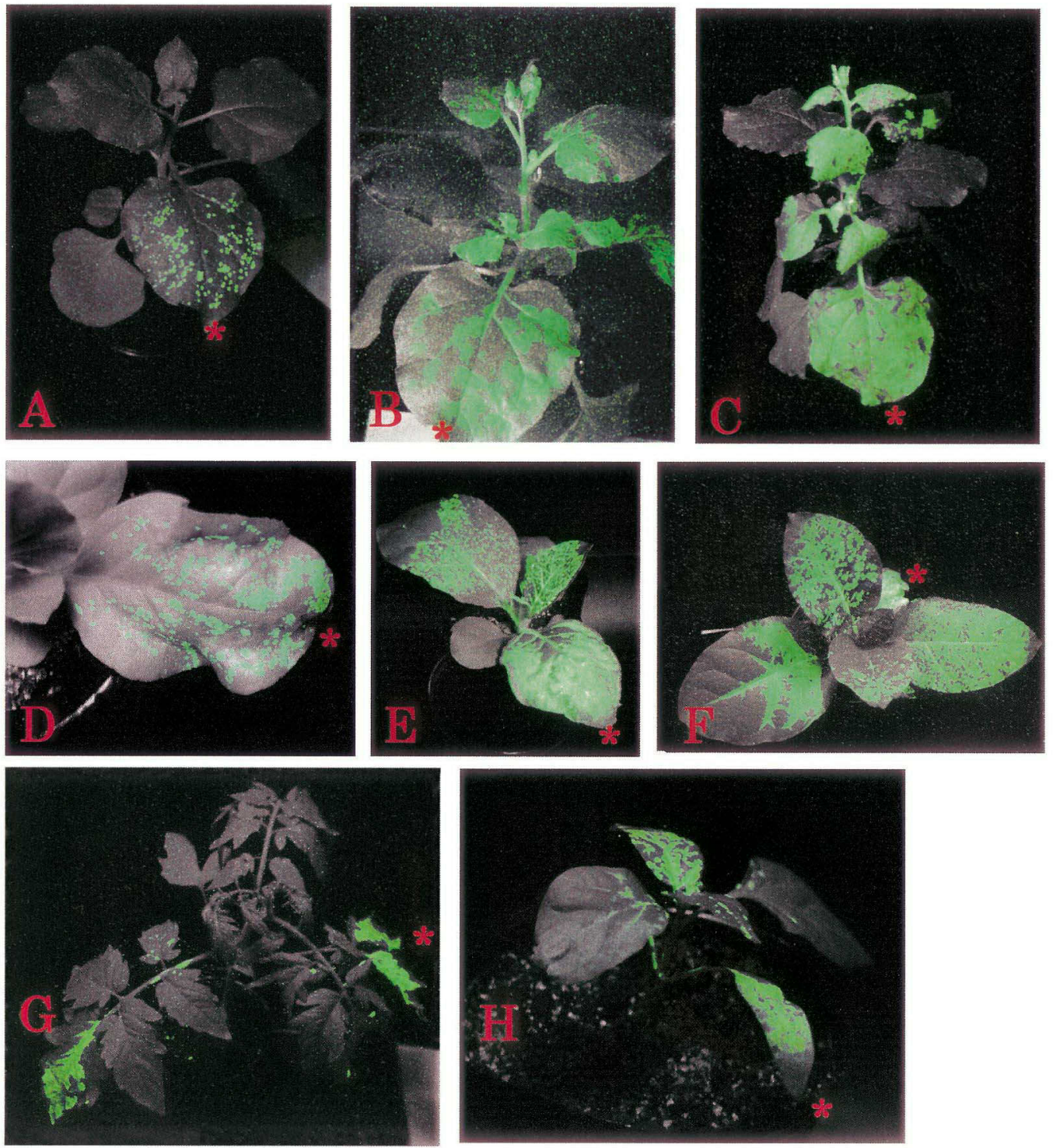

Fig. 4 TocJ/GFP inoculated plants.

(A-C) N. benthamiana with TocJ/GFP at (A) 3 dpi, (B) 7 dpi and (C) 12 dpi.

(D-F) N. tabacum cv. Samsun with TocJ/GFP at (D) 3 dpi, (E) 7 dpi and (F) 12 dpi.

(G) L. esculentum with TocJ/GFP at $10 \mathrm{dpi}$.

(H) C. annuum var. angulosum with TocJ/GFP at $7 \mathrm{dpi}$.

Two images are merged, an image of GFP fluorescence under a mercury lamp with GFP plus filter set (Leica) and an image under visible light. The asterisks indicate inoculated leaves. 
shuffling improved the movement and host range properties of the 30B vector (Toth et al., 2002). Likewise it is still possible that we can improve our TocJ vector with better properties.

\section{Acknowledgments}

We thank Dr. Tetsuo Okuno at Kyoto University for providing the cDNA clone of the TMGMV Japanese strain, Drs Meshi Tetsuo at Kyoto University and Shinya Tsuda at the National Agricultural Research Center for suggestion and information. This work was supported in part by "Molecular Mechansims of Plant-Pathogenic Microbe Interaction" and "Spatiotemporal Network of RNA Information Flow" grants-in-aid for scientific research on priority areas (A) from the Ministry of Education, Culture, Sports, Science, and Technology of Japan (Nos. 08680733 and 14035215) to Y.W.

\section{References}

Bendahmane, M., Koo, M., Karrer, E., Beachy, R. N., 1999. Display of epitopes on the surface of tobacco mosaic virus: Impact of charge and isoelectric point of the epitope on virus - host interactions. J. Mol. Biol., 290: 9 -20 .

Dawson, W. O., Lewandowski, D. J., Hilf, M. E., Bubrick, P., Raffo, A. J., Shaw, J. J., Grantham, G. L., Desjardins, P. R, 1989. A tobacco mosaic virus -hybrid expresses and loses an added gene. Virology, 172: 285 292.

Donson, J., Kearney, C. M., Hilf, M. E., Dawson, W. O., 1991. Systemic expression of a bacterial gene by a tobacco mosaic virus-based vector. Proc. Natl. Acad. Sci. U: S. A., 88: 7204-7208.

Fitchen, J., Beachy, R. N., Hein, M. B., 1995. Plant virus expressing hybrid coat protein with added murine epitope elicits autoantibody response. Vaccine, 13: $1051-1057$.

Franconi, R., Roggero, P., Pirazzi, P., Arias, F. J., Desiderio, A., Bitti, O., Pashkoulov, D., Mattei, B., Bracci, L., Masenga, V., Milne, R. G., Benvenuto, E., 1999. Functional expression in bacteria and plants of an scFv antibody fragment against tospoviruses. Immunotechnology, 4: $189-201$.

Grdzelishvili, V. Z., Chapman, S. N., Dawson, W. O., Lewandowski, D. J., 2000. Mapping of the Tobacco mosaic virus movement protein and coat protein subgenomic RNA promoters in vivo. Virology, 275: 177 192.

Hamamoto, H., Sugiyama, Y., Nakagawa, N., Hashida, E., Matsunaga, Y., Takemoto, S., Watanabe, Y., Okada, Y., 1993. A new tobacco mosaic virus vector and its use for the systemic production of angiotensin- $\mathrm{I}$-converting enzyme inhibitor in transgenic tobacco and tomato. Bio/Technology, 11: 930-932.

Hendy, S., Chen, Z. C., Barker, H., Santa Cruz, S., Chapman, S., Torrance, L., Cockburn, W., Whitelam, G. C.,
1999. Rapid production of single-chain Fv fragments in plants using a potato virus $\mathrm{X}$ episomal vector. $\mathrm{J}$. Immunol. Methods, 231: 137-146.

Imai, Y., Matsushita, Y., Sugimura, T., Terada, M., 1991. A simple and rapid method for generating a deletion by PCR. Nucleic Acids Res., 19: 2785.

Kawakami, S., Watanabe, Y., 1997. Use of green fluorescent protein as a molecular tag of protein movement in vivo. Plant Biotechnol., 14: 127-130.

Kovalic, D., Kwak, J. H., Weisblum, B., 1991. General method for direct cloning of DNA fragments generated by the polymerase chain reaction. Nucleic Acids Res., 19: 4560 .

Kumagai, M. H., Turpen, T. H., Weinzettl, N., DellaCioppa, G., Turpen, A. M., Donson, J., Hilf, M. E., Grantham, G. L., Dawson, W. O., Chow, T. P., Piatak, J. M., Grill, L. K., 1993. Rapid, high-level expression of biologically active alpha - trichosanthin in transfected plants by an RNA viral vector. Proc. Natl. Acad. Sci. U. S. A., 90: 427-430.

Laemmli, U. K., 1970. Cleavage of structural proteins during the assembly of the head of bacteriophage T4. Nature, 227: $680-685$.

Lim, A. A., Tachibana, S., Watanabe, Y., Wong, S. M., 2002. Expression and purification of a neuropeptide nocistatin using two related plant viral vectors. Gene, 289: $69-79$.

Meshi, T., Ishikawa, M., Motoyoshi, F., Semba, K., Okada, Y., 1986. In vitro transcription of infectious RNAs from full- length cDNAs of tobacco mosaic virus. Proc. Natl. Acad. Sci. U. S. A., 83: 5043-5047.

Morishima, N., Ido, T., Hamada, H., Yoshimoto, E., Mizumoto, H., Takeuchi, S., Hikichi, Y., Okuno, T., 2003. Infectious in vitro transcripts from a cDNA clone of Tobacco Mild Green Mosaic Tobamovirus and it's bidogical activity in host and non-host plants. J. Gen. Plant Pathol. (in press).

Ogawa, H., Inouye, S., Tsuji, F. I., Yasuda, K., Umesono, K., 1995. Localization, trafficking, and temperaturedependence of the Aequorea green fluorescent protein in cultured vertebrate cells. Proc. Natl. Acad. Sci. U. S. A., 92: 11899-11903.

Ohno, T., Aoyagi, M., Yamanashi, Y., Saito, H., Ikawa, S., Meshi, T., Okada, Y., 1984. Nucleotide sequence of the tobacco mosaic virus (tomato strain) genome and comparison with the common strain genome. J. Biochem., 96: 1915-1923.

Porta, C., Spall, V. E., Loveland, J., Johnson, J. E., Barker, P. J., Lomonossoff, G. P., 1994. Development of cowpea mosaic virus as a high-yielding system for the presentation of foreign peptide. Virology, 202: $949-$ 955.

Roggero, P., Ciuffo, M., Benvenuto, E., Franconi, R, 2001. The expression of a single-chain Fv antibody fragment in different plant hosts and tissues by using Potato virus $X$ as a vector. Protein Expr. Purif, 22: 70-74.

Saito, T., Yamanaka, K., Watanabe, Y., Takamatsu, N., Meshi, T., Okada, Y., 1989. Mutational analysis of the coat protein gene of tobacco mosaic virus in relation to 
hypersensitive response in tobacco plants with the $\mathrm{N}^{\prime}$ gene. Virology, 173: 11-20.

Shirzadegan, M., Chrisitie, P., Seemann, J. R., 1991. An efficient method for isolation of RNA from tissue cultured plant cells. Nucleic Acids Res., 19: 6055.

Shivprasad, S., Pogue, G. P., Lewandowski, D. J., Hidalgo, J., Donson, J., Grill, L. K., Dawson, W. O., 1999. Heterologous sequences greatly affect foreign gene expression in tobacco mosaic virus-based vectors. Virology, 255: $312-323$.

Skuzeski, J. M., Nichols, L. M., Gesteland, R. F., Atkins, J. F, 1991. The signal for a leaky UAG stop codon in several plant viruses includes the two downstream codons. J. Mol. Biol., 218: 365-373.

Sugiyama, Y., Hamamoto, H., Takemoto, S., Watanabe, Y., Okada, Y., 1995. Systemic production of foreign peptides on the particle surface of tobacco mosaic virus. FEBS Lett., 359: 247 - 250.

Takamatsu, N., Ishikawa, M., Meshi, T., Okada, Y., 1987. Expression of bacterial chloramphenicol acetyltransferase gene in tobacco plants mediated by TMV-RNA. EMBO J., 6: $307-311$.

Takamatsu, N., Watanabe, Y., Meshi, T., Okada, Y,, 1990a,
Mutational analysis of the pseudoknot region in the $3^{3}$ noncoding region of tobacco mosaic virus RNA. J. Virol., 64: 3686-3693.

Takamatsu, N., Watanabe, Y., Yanagi, H., Meshi, T., Shiba, T., Okada, Y., 1990b. Production of enkephalin in tobacco protoplasts using tobacco mosaic virus RNA vector. FEBS Lett., 269: $73-76$.

Toth, R. L., Pogue, G. P., Chapman, S., 2002. Improvement of the movement and host range properties of a plant virus vector through DNA shuffling. Plant J., 30: 593600 .

Turpen, T. H., Reinl, S. J., Charoenvit, Y., Hoffman, S. L, Fallarme, V., Grill, L.K., 1995. Malarial epitopes expressed on the surface of recombinant tobacco mosaic virus. Bio/Technology, 13: $53-57$.

van Belkum, A., Abrahams, J. P., Pleij, C. W. A., Bosch, L., 1985. Five pseudoknots are present at the 204 nucleotides long 3' noncoding region of tobacco mosaic virus RNA. Nucleic Acids Res., 13: 7673-7686.

Watanabe, Y., Meshi, T., Okada, Y,, 1987. Infection of tobacco protoplasts with in vitro transcribed tobacco mosaic virus RNA using an improved electroporation method. FEBS Lett., 219: 65-69. 